\title{
Recibir princesas y enterrar reinas (Zamora 1501 y 1504)
}

\author{
Manuel Fernando Ladero Quesada *
}

\begin{abstract}
RESUMEN
Entre las fiestas que tienen lugar en las ciudades medievales, hay algunas celebraciones que, por su carácter excepcional, adquieren una mayor relevancia y repercusión sobre la memoria colectiva de sus habitantes, destacan aquellas que tienen como protagonistas, de una manera $u$ otra, a personajes de la realeza. En el presente trabajo se comentan dos acontecimientos que tienen lugar en la ciudad de Zamora en los primeros años del siglo XV. La visita a la ciudad en 1501 de Catalina de Aragón, hija menor de los Reyes Católicos, de paso hacia Inglaterra para contraer matrimonio, sucesivamente, con los dos hijos de

Enrique VII; y los actos que se organizan para honrar la memoria de la reina Isabel -exequias- , fallecida en noviembre de 1504. El artículo se acompaña de una breve selección documental, con textos procedentes del Archivo Histórico Nacional y el Archivo Histórico Provincial de Zamora.
\end{abstract}

\author{
ABSTRACT \\ Bettween the festivities of the medieval \\ cities, there are some celebrations \\ that, for their exceptional cháracter, \\ acquire repercussion in the colective \\ memory of their habitants, bettween \\ them exist that ones that have as main \\ cháracters the royal family. In this \\ report are comentd two events in \\ Zamora in the first years of the XVI \\ century. The visit in 1501 to the city of \\ Catalina de Aragón, daugther of the \\ kings Ferdinand and Elisabeth, in her \\ journey to England to get married, \\ successively, with two Henry's VII \\ sons; and the acts thet were organised \\ to honour queen's Elisabeth memory \\ (exequias), death in November of \\ 1504. The study is accompained by a \\ short documental selection, with text \\ from the National Historical Archives \\ and Historical Archives of Zamora.
}


En épocas de paz y en el terreno de las celebraciones urbanas, sean estas festivas o luctuosas, pocos son los acontecimientos que son capaces de romper la rutina de la vida cotidiana de una pequeña ciudad ya que todas aquellas festividades que se derivan o del calendario anual, sea este eclesiástico o resultado de los ciclos de la actividad económica, o de las celebraciones que tienen su origen en el ámbito privado (bodas, nacimientos, etc), no cabe considerarlas como ajenas a esa rutina normal. Tienen que ser eventos que en su origen o justificación sean únicos e irrepetibles, aunque luego en su desarrollo como tales fiestas ciudadanas no ofrezcan demasiadas diferencias con las habitualmente repetidas todos los años ${ }^{1}$.

Fiestas ordinarias, como cualquier otra ciudad, Zamora en los siglos bajomedievales tenía varias: San Ildefonso, patrono de la ciudad, el 26 de mayo, San Juan en junio, Santiago en julio y Santa María en septiembre, todas ellas salvo el día del patrón de la ciudad, íntimamente ligadas al calendario agricola ${ }^{2}$. Son las celebraciones ocasionales las que ahora nos interesan; en las páginas que siguen intentaremos glosar, sobre la base de las referencias documentales que se han conservado, el desarrollo de dos de esos acontecimientos de carácter singular. El primero, si no exclusivo de Zamora si por lo menos compartido con pocas ciudades - nuestra búsqueda de referencias al mismo en otras ciudades ha resultado, de momento, baldía - y de carácter festivo: el paso por la ciudad de Catalina de Aragón, hija de los reyes, de camino a su destino como reina de Inglaterra. El segundo de carácter luctuoso y compartido con todo el reino aunque, al fin y al cabo, excepcional: la recepción en la ciudad de la noticia de la muerte de la reina Isabel y las medidas que se toman para honrar su memoria ${ }^{3}$.

Síntesis sobre todo lo relativo a la fiesta en época medieval con abundantes referencias bibliográficas en LADERO QUESADA, Miguel A.: "La fiesta en la Europa mediterránea medieval», Cuadernos del CEMYR n. 2 (1994), pp.11-52. Reflexiones interesantes sobre la fiesta como elemento de legitimación y propaganda pueden verse en ASENJO, Maria: “Las ciudades», en (J.M. Nieto, director) Orígenes de la monarquía hispánica: propaganda y legitimación (CA. 1400-1520). Madrid, Dykinson 1999, pp. 105-140.

2 Para lo relacionado con Zamora en esta época véase LADERO QUESADA, Manuel F.: Zamora en la época de los Reyes Católicos. Economía y gobierno. Zamora, 1991 y Libros de acuerdos del consistorio de la ciudad de Zamora (1500-1504). Zamora, 2000.

3 En un trabajo anterior y junto a otros asuntos ya nos ocupamos de esta cuestión de forma mucho más escueta y conociendo menos documentación. Vid. LADERO QUESADA, Manuel F. : "llustraciones sobre Zamora a comienzos de la modernidad según las actas de las reuniones del consistorio (1500-1504)", Studia Zamorensia, segunda etapa, vol I (1994).pp 143-158. 


\section{LA PRINCESA DE GALES EN ZAMORA.}

Es evidente que tras la finalización de la guerra civil, en la que la ciudad va a jugar un papel destacado - no sólo como escenario del conflicto bélico sino también por su intrínseco valor estratégico -, el protagonismo o la presencia de Zamora en la vida del reino va a ser si no marginal sí, al menos, periférico, tanto desde el punto de vista económico como desde el punto de vista político como consecuencia, en este aspecto, de la definitiva normalización de relaciones con el vecino Portugal, la concentración de todos los esfuerzos en la culminación del proceso reconquistador y, en relación directa con el desarrollo de la política exterior mediterránea y europea de los Reyes Católicos, la marginación de Zamora como lugar de paso o estancia de los reyes y su corte, los cuales por muy variadas razones, suficientemente conocidas, prefirieron otras ciudades como Medina del Campo, Valladolid o Segovia para sus estancias en los territorios de la meseta.

Es por esto que el anuncio de la visita a la ciudad de un miembro de la familia real se convierta para Zamora en un hecho de relevancia singular en su devenir cotidiano del que la documentación municipal nos da cumplida cuenta. En efecto se trata del previsible paso por la ciudad de la princesa Catalina, hija de los reyes, de camino hacia Inglaterra ya convertida en Princesa de Gales ${ }^{4}$. $Y$ digo previsible porque el texto de las actas municipales donde se da cuenta de ello así lo da a entender: "sobre la venida que se dise que viene para esta çibdad»; y no resulta extraña esta incertidumbre si se tiene en cuenta que el cortejo principesco deambuló más de tres meses por los territorios del reino desde su salida de Granada el 21 de mayo hasta el primer embarque en La Coruña a mediados de agosto ${ }^{5}$.

4 Fue la menor de las hijas de los Reyes Católicos, nació en Alcalá de Henares -en la Torre del Arzobispo Tenorio- el 16 de diciembre de 1485 y fue llamada así en recuerdo de su bisabuela Catalina de Lancaster. El matrimonio con Arturo, hijo de Enrique VIl y heredero de la corona inglesa fue concertado en 1489(27 de marzo, tratado de Medina del Campo, suscrito con los embajadores ingleses Thomas Savage y Ricardo Nanfan), cuando Catalina contaba tan sólo tres años, celebrándose la boda por poderes en 1499. Como es sabido, tras enviudar contraerá segundo matrimonio con Enrique VIII y su posterior divorcio traerá consigo el nacimiento de la iglesia anglicana. Catalina murió el 7 de enero de 1536. Vid. SuÁrEZ, Luís: Historia de España 7. Los Trastámara y los Reyes Católicos. Madrid, ed. Gredos, 1985 pp. 285 y 375 . Sobre los regalos que recibieron los embajadores ingleses en Medina del Campo vid. Nieto Soria, J.M, ob. cit., p. 412-413. La mejor obra de referencia sobre Catalina es, sin duda, la de MATTINGLY, G: Catalina de Aragón. Madrid, ed. Palabra, 1998, aunque con escasa utilidad para los «años castellanos" de la princesa.

5 SuÁREZ, Luís, ob. cit., p. 380. MATtingly, G., ob. cit., p. 39-40. Una tormenta obligó a su flota a refugiarse en Laredo donde permanecería hasta septiembre. La boda no se celebró hasta el 14 de noviembre en la abadía de Westminster. 
En todo caso, a comienzos de junio ya hay constancia cierta en la ciudad de que la princesa va a pasar por ella y, de inmediato, los regidores comienzan los preparativos para recibirla. Dos son las iniciativas que inicialmente se toman, una de carácter práctico, la solicitud a los reyes para que autoricen efectuar un repartimiento extraordinario para cubrir los gastos de la estancia, y otra, aparentemente casual e intrascendente pero que sin duda tiene un trasfondo más profundo dentro del juego de relaciones internas de la oligarquía urbana, el levantamiento de la pena de destierro para todos aquellos regidores y caballeros de la ciudad que lo padecen para que puedan estar presentes en las celebraciones ${ }^{6}$.

Pocos días después, las actas concejiles registran el acuerdo de escribir al comendador mayor - escrito así en el original, sin duda se trata del Camarero Mayor don Pedro Manrique, responsable máximo de la comitiva de la princesa - para pedirle confirmación expresa de la visita y solicitar su consejo sobre lo que la ciudad debía disponer para agasajar adecuadamente a la Princesa. El mismo día se convoca también a los procuradores de los vecinos de la tierra para que estén presentes y participen de las decisiones que al respecto se tomen?

Dos días antes de la llegada de la princesa se adoptan medidas para el alojamiento de las tropas de la capitanía de García Alonso, que acudían a la ciudad para rendir honores a doña Catalina. El capitán quedó alojado en la posada de Villafañe (personaje mencionado con cierta frecuencia en la documentación municipal, por ejemplo, será el avalista del siguiente corregidor de la ciudad don Sancho de Rojas, al que más adelante mencionaremos), y sus tropas en otras cercanas de la calle de El Riego y la zona de la ciudad conocida por Barrionuevo ${ }^{8}$.

La víspera de la llegada, una vez recibida la respuesta del mencionado camarero mayor, los regidores acuerdan en contenido del regalo para la princesa el cual, no podía ser de otro modo, cabe calificar redundantemente de principesco:

"Acordaron que por quanto la señora prinçesa de gales ha de venir a esta çibdad mañana sabado e es mucha rason que sea servida en ella espeçialmente segund to que escribio e enbio desir el comendador (sic) mayor della a esta çibdad de servir a su aliteça con dies terneras e quatro toros e con ocho cargas de vino y veynte cargas de çevada y dose dosenas de aves y

\footnotetext{
6 Libros de acuerdos, ob. cit., p.150, sesión del 8 de junio de 1501. Ordenan que la carta sea llevada a Valladolid por un hidalgo y el designado será Gómez Maldonado

Ibidem, p.153, sesión del 15 de junio de 1501.

8 Ibidem, p. 157, sesión del día 17 de junio de 1501.
} 
çinquenta botes de conservas y çient libras de confites y teynta y ocho hachas lo qual consyntio Françisco de Salamanca procurador general por ser pro e onrra desta çibdad e su tierra» ${ }^{9}$.

Enseguida haremos referencia al precio de semejante dispendio, si bien conviene adelantar que no hay una exacta coincidencia entre lo previsto y lo que realmente se ofreció a la princesa y su séquito. También se acordó otra cuestión importante y que va más allá de lo meramente protocolario; el honor de acompañar al lugarteniente del corregidor (el corregidor había solicitado la reglamentaria licencia de 90 días el 22 de febrero, si bien no se reincorporó a su puesto hasta el 3 de septiembre) para hacer entrega de los presentes cupo a los regidores Juan Docampo y Alonso de Mazariegos.

Dentro del programa de la visita todavía cabía hacer algo más. Existía una costumbre ancestral por la cual los monarcas o personajes principales que visitaban la ciudad acudían a honrar las reliquias de su patrón, San Ildefonso. Los regidores no dudan que este será también el deseo de Catalina, aunque no deja de llamar la atención de nuevo el tono indirecto utilizado: "e porque se dise que la señora prinçesa quiere ver los restos del señor sant Ylefonso", y sortean entre ellos quien la acompañará para abrir el cofre donde estaban depositadas las reliquias, correspondiendo tal privilegio a Francisco Docampo (que se responsabilizará de la custodia de la llave del cofre que normalmente se guardaba en el arca del consistorio donde se custodiaban los privilegios y documentos importantes de la ciudad) y a García de Ledesma ${ }^{10}$.

Decía antes que estas designaciones «por sorteo» van más allá de lo estrictamente protocolario, en efecto resulta significativo que sean estos cuatro regidores los que acaparen el protagonismo local de la visita porque todos ellos ocupan, en este momento concreto de la historia de la ciudad, los escalones más altos de la jerarquía social, no sólo por razones históricas ya que sus familias vienen ocupando regidurías a lo largo

9 No se ha conservado la carta del camarero de la princesa y no sabemos si en ella se haría referencia a otras cuestiones como las ropas que debian vestir los regidores $u$ otras cuestiones como el uso o no de palios, aunque es posible que no hiciera referencia a ello dado que, en sentido estricto no se trata de una "entrada" sino de una visita pasajera. Un buen ejemplo sobre los preparativos necesarios para una entrada principesca, relativo en este caso a la entrada de los príncipes Felipe y Juana en Valladolid a finales de ese mismo año, puede verse en NiETo SoRIA, J.M., ob. cit., pp. 442-443. Sobre las «entradas reales» en general, véase el trabajo de R. De ANDRÉS, "Las "entradas reales" castellanas en los siglos XIV y XV según las crónicas de la época», En la España Medieval 4 (1984), pp. 48-62

10 Libros de acuerdos, ob. cit., pp. 158-159. Sesión del 18 de junio de 1501. 
de todo el siglo xv, sino porque durante el pasado conflicto con Portugal han sido ellas precisamente las más beligerantes en favor de los intereses de los padres de la princesa (los Mazariegos defendiendo las torres del puente de la ciudad, los Docampo y los Ledesma participando en la contienda bélica tanto al mando de la hueste concejil como apoyando a los Enriquez, condes de Alba y Aliste), frente a las actitudes dubitativas o incluso contrarias de otras familias de la oligarquía zamorana como los Valencia o los Porres. Igualmente, aunque en menor medida, también llama la atención la aparente marginación de los integrantes de la pequeña nobleza de la ciudad no presente en el regimiento, grupo con el que apenas dos años antes habían alcanzado los regidores un amplio acuerdo en el que, entre otros muchos asuntos, se incluye el reparto a la hora de designar algunos oficios concejiles y otros cargos como las procuraciones de cortes.

Por fin el sábado 19 de junio de 1501 la princesa llega a Zamora. Por desgracia no se ha conservado ningún vestigio documental del desarrollo del acontecimiento, pero no cuesta demasiado imaginarlo: la recepción extramuros y los discursos de bienvenida por parte de las autoridades municipales, las calles lo más limpias posible y engalanadas para la ocasión, los zamoranos principales y sus mujeres vestidos con sus mejores ropas, el recorrido de la comitiva ${ }^{11}$ por las calles, aclamada por todos los vecinos de la ciudad y muchos venidos de las comarcas cercanas, hasta alcanzar la plaza de San Juan donde, frente al ayuntamiento, contemplaría el alarde de las tropas de la capitanía de García Alonso, la visita a la iglesia de san Pedro para honrar los restos del santo, el banquete donde se consumiría buena parte del regalo de la ciudad, más tarde la corrida de toros en el campo de la Feria o en la plaza del mercado y, por último, la cena, la fiesta y el alojamiento de la princesa en el palacio de los Enriquez, sus parientes Probablemente la estancia debió prolongarse varios días, puesto que el lunes no tuvo lugar la habitual reunión del Consistorio, no se cele-

11 Como es lógico la comitiva de una princesa que se iba del reino con la intención de no volver tenía que ser necesariamente amplia; Mattingly —ob. cit., p. 39- nos la describe así: «mandaba su escolta el conde de Cabra, héroe de las guerras de Granada, que, con Alonso de Fonseca, arzobispo de Santiago y el obispo de Mallorca, era uno de los tres altos comisarios que estarian loco parentis, en su boda. Además de los arqueros y caballeros que la dejarian en el barco; de los nobles, clérigos y letrados, con sus criados y lacayos, cuya tarea estaría cumplida cuando la vieran casada, sana y salva, se llevó una casa permanente de unas setenta personas. Iban desde doña Elvira Manuel, su «dueña», y el marido de doña Elvira, don Pedro Manrique, su Camarero Mayor, hasta lavanderas, pajes, cocineros y panaderos, pasando por don Alejandro Geraldini (su antiguo tutor y ahora su confesor y capellán principal), un segundo camarero mayor, un veedor, un copero mayor, un repostero de estrados, cuatro caballerizos y diversas damas de honors. 
bró hasta el día 25 viernes, aunque no hay constancia de que tuviese lugar ninguna otra celebración o festejo público.

Pero acabada la fiesta llega el momento de pagar y hay que reconocer que, al menos en este caso concreto, la burocracia concejil estuvo especialmente diligente pues el mismo día 20 de junio los regidores tienen ya conocimiento exacto de lo gastado, en que se ha gastado y las personas a las que hay que pagar ${ }^{12}$. El monto total alcanzó los 35.841 maravedís, sin embargo en la siguiente reunión del consistorio los regidores reiteran su petición a los reyes para que autoricen el repartimiento de 40.000 maravedís que ya habían solicitado anteriormente:

\begin{abstract}
«Acordaron que se escriba una carta al señor corregidor y otra Alonso Ordoñez (regidor que circunstancialmente se encontraba en Valladolid) hasiendoles saber la venida aquí de la señora prinçesa de gales e como esta çibdad la sirivió en algunas cosas fasta en quantia de 40000 maravedís e porque no ay dineros de propios que procuren como sus alteças manden dar liçençia para repartir los dichos maravedís para los pagar a las personas que se debe e que Alonso Ordoñez de una petiçion sobrello en virtud del poder que tiene de la çibdad» ${ }^{13}$.
\end{abstract}

El ahorro proviene del hecho de que no se «sirvió» a la princesa con todo lo que estaba previsto: las diez terneras se convierten en ocho, los cuatro toros para correr sólo fueron tres y las treinta y ocho hachas de cera se quedaron en treinta. Sin embargo se reitera la petición inicial de cuarenta mil maravedís y quizás ello obedezca a una previsora pillería contable de los regidores que ese mismo día 25 de junio mandan librar al mayordomo del concejo con cargo a los propios de la ciudad, tres mil maravedís «que el juro que avía gastado en la bebida de Sant Juan de Junio que se dio a la justiçia e regidores e cavalleros e escuderos desta çibdad", es decir el gasto que se produce en una de las celebraciones institucionales ordinarias de la ciudad y que tuvo lugar precisamente el día anterior, y también para cubrir otros pequeños gastos no contemplados en la cuenta general como los 3 reales que ese mismo día se libraron a Mújica andador del concejo "de tres días que estovo en yr a saber la venida de la señora prinçesa de gales por ver sy venia por esta çibdad».

La autorización para efectuar el repartimiento - la parte correspondiente a la ciudad se recaudaría mediante sisa en las carnicerías- se re-

12. AHN. Diversos. Concejos y ciudades, leg. 262 doc. 13/3. Vid. Apéndice Documental, documento 1.

13 Libros de Acuerdos, ob. cit., p.159. Sesión del 25 de junio de 1501. 
cibe el día 16 de agosto ${ }^{14} y$ éste se efectuará el mismo año conjuntamente con el de otras cantidades destinadas a gastos de pleitos y salarios varios ${ }^{15}$. A los habitantes de la ciudad, principales disfrutadores del festejo les correspondió pagar 5440 maravedís, apenas el $13,6 \%$ del monto total. El día 25 de octubre se ordena en consistorio pagar lo que se debía «a todas las personas que dieron alguna cosa para el serviçio de la señora prinçesa”.

Sin embargo, y como dato final, no podemos dejar de significar que esta cantidad es prácticamente irrisoria si la comparamos con el enorme "castigo» fiscal que ese mismo año sufrieron los habitantes de la tierra de Zamora, los de la ciudad estaban exentos, como consecuencia de los matrimonios de la princesa Catalina - su dote matrimonial se acordó en 200.000 escudos ${ }^{16}$ - y de su hermana, la princesa María, con Manuel de Portugal, cuya dote se fijó en 200.000 doblas ${ }^{17}$. La mayor derrama que conocemos de estos años pues el monto total del repartimiento quedó fijado en 669.185 maravedís que se recaudaron en el mes de mayo de $1501^{18}$.

\section{LA MUERTE DE LA REINA}

Los funerales reales son también, en cierto sentido, una fiesta o celebración pública en la que encontramos la otra cara de la moneda de la alegría propia de otras, aunque los elementos símbólicos referidos a la re-

14 Ibidem, p. 174. Sesión del 16 de Agosto de 1501: «Alçaron el enbargo que esta puesto en el salario de los regidores para los serviçios de la señora prinçesa porque vino provision de sus alteças para haser repartimiento del dicho serviçio».

15 AHPZ. Fondo Municipal Nuevo. Propios. Caja B-1 (signatura provisional). Vid. Apéndice documental, documento 2.

16 SUAREZ, L., cb. cit., p. 285.

17 Ibidem, p. 380.

18 AHPZ. Fondo Nuevo Municipal. Caja B-1 (catalogación provisional). «Repartimiento de seysçientos e çinquenta e nueve mill e dosientos e noventa e seys maravedis que el Rey e la Reyna nuestros señores mandaron repartyr este presente año de mill e quinientos e un años por los logares de la tierra desta çibdad de Çamora para las dotes de las señoras ynfantas e mas quinse maravedis al millar de los susodichos que sus alteças mandaron repartyr de los derechos del recebtor que montan nueve mill e ochosientos e ochenta y nueve maravedis e medio que son todos seysçientos e sesenta e nueve mill e çiento e ochenta e çinco maravedis e medio el qual dicho repartimiento se fiso en catorse dias de mayo del dicho año por las cañamas acostumbradas estando presentes Juan de Porras e Juan de Masariegos regidores e los tres procuradores de la dicha tierra que salio cada cañama a quatroçientos e treynta e çinco maravedis». Sigue la relación con lo que corresponde pagar a cada lugar. Recibió este repartimiento Sebastián de Medina, platero, por poder de Fernando de Ledesma. 
presentación del poder y a la fijación de las jerarquías sociales sean similares. En estos casos, tal y como señala Asenjo, el luto era obligatorio y se deban instrucciones concretas de cómo respetarlo ${ }^{19}$. El fallecimiento de un rey o de una reina era sin duda un acontecimiento que marcaba profundamente la memoria colectiva; puede resultar un tanto sorprendente que en un período histórico cargado de hechos de evidente transcendencia como son los años finales del reinado conjunto de los Reyes Católicos (descubrimientos ultramarinos, guerras en Italia, matrimonios de estado, etc), éstos no dejen ninguna o muy escasa huella en las fuentes documentales de origen municipal, pero no lo es tanto si consideramos que las actas son el trasunto o el espejo de una realidad reducida geográficamente -utilizando una expresión anacrónica, «la Castilla profunda»- en su dimensión más cotidiana ajena a los grandes fastos históricos y que sólo muy excepcionalmente se ve afectada por ellos.

La figura y la obra de la reina Isabel ha sido estudiada desde prácticamente todos los ángulos por numerosos autores cuya nómina y aportaciones es baladí indicar aquí. Sin embargo, al menos en lo que nosotros conocemos, existe una pequeña laguna, casi total, en este amplio conocimiento de su trayectoria, y ésta es precisamente la aproximación al cuándo y al cómo fue recibida la noticia de su muerte por sus súbditos de a pie de todos los lugares del reino y que medidas se adoptaron para honrar su memoria ${ }^{20}$. El contenido de las actas concejiles y algunos otros documentos de tipo fiscal nos permiten, para el caso de Zamora, contestar al menos parcialmente a estas preguntas.

El precario estado de salud de la reina debía ser sin duda algo conocido en todo el reino mucho tiempo antes de la fecha de su fallecimiento ${ }^{21}$, por eso no es de extrañar que la primera noticia que nos ofrecen las actas

19 Ob. Cit. p. 137. Reseña las medidas tomadas por el regimiento de Córdoba con ocasión del fallecimiento del príncipe Juan en 1497, entre otras la prohibición de celebrar bodas, la prohibición a los barberos de ejercer su oficio (sic), la prohibición de ropas de seda y de determinados colores, etc.

20 La única aproximación a este acontecimiento que conocemos, partiendo de documentación local, es la de LlomparT, G.: «Cortejos luctuosos y patrióticos en la Mallorca medieval», Boletin de la Sociedad Arqueológica Luliana XXXIII (1972), pp. 314-331.

21 Desde el mes de julio la reina estaba instalada en Medina del Campo. En septiembre su hija Juana y su marido Felipe fueron avisados por el rey Fernando para que tuviesen dispuesto su regreso a Castilla, pues el desenlace fatal se preveía inminente. La reina firmó su testamento el día 12 de octubre (L. SuÁrEz, ob. cit., p. 395). La precaria salud de Isabel también era conocida más allá de los Pirineos: en algún momento de 1504 se produce la visita a Castilla del príncipe Prospero Colonna para resolver asuntos relacionados con el reino de Nápoles y según reseñan las crónicas «dijo al rey que venía a ver a aquella que desde la cama mandaba en el mundo» (Cfr. Cronicón de Valladolid. Valladolid 1984 (ed. Facsimil), p. 219. 
sean una muestra de la preocupación por su estado: la celebración de una procesión por la salud de la reina el día 3 de noviembre, es decir, poco más de veinte días antes de su fallecimiento ${ }^{22}$.

Las actas guardan silencio hasta el día siguiente al del óbito de la reina, el miércoles 27 de noviembre ${ }^{23}$. Se trata de un consistorio de carácter extraordinario (los ordinarios eran los lunes y los viernes) y además en un lugar inusual: las casas del corregidor Sancho de Rojas. Se trata monográficamente la muerte de la reina el día anterior y el texto tiene interés fundamentalmente por dos motivos; el primero porque reseña la hora del fallecimiento en un documento municipal, ajeno por tanto a la administración central y a los documentos que de ella emanan: «dixeron que por quanto la reyna doña Ysabel nuestra señora fallesçio ayer martes en Medina del Campo entre las onse y las dose del mediodia». Probablemente además tal conocimiento no es fruto de una comunicación escrita sino de la condición de testigo próximo al suceso del propio corregidor, que no había presidido la reunión del consistorio celebrada en día anterior y que, sin embargo, se encuentra en Zamora en la mañana del día 27 , parece pues una fuente absolutamente fiable ${ }^{24}$.

El segundo motivo de interés radica en que los regidores toman acuerdos sobre la manera en que la ciudad debe honrar la memoria de la reina:

«que tome luto la justiçia e regidores de paño negro segund lo dispone la prematica de sus alteças e que se de el dicho luto al corregidor e al bachillar allcalde e a los regidores que estuviesen en la çibdad quando se hisieren las obsequias e el escrivano del conçejo a cada uno trese varas e media para la loba e capirote e sayon e caperuça e que se de de paño diesyocheno de Segovia e cometieron al bachiller alcalde e a Luys de Mella que busquen los dichos paños e hagan los preçios dellos por lo menos que pudieren porque lo ha de pagar la çibdad».

22 Libros de Acuerdos, ob. cit., p.369. Sesión del 2 de noviembre de 1504.:"Acordaron que la justiçia e regidores vayan a la proçesion que se ha de haser el domingo por la salud de la reyna nuestra señora e el regidor que no fuere que pague çient maravedis de pena».

23 Ibidem, p. 372.

24 El corregidor no se encuentra en la ciudad desde al menos el mes de septiembre - momento en que comienzan las actas conservadas de 1504- y no hay duda de que durante este tiempo se encuentra en la corte, pues allí le remiten los regidores varias cartas para que se ocupe de la resolución de asuntos que atañen a la ciudad. Es él pues personalmente el que trae la noticia del fallecimiento pues la comunicación oficial, mediante cédula del rey Fernando, no llegará a Zamora hasta el día siguiente 28. Por lo demás, la hora de la muerte coincide totalmente con la señalada por los cronistas coetáneos como Galíndez de Carvajal o el Cura de los Palacios. 
De nuevo llama la atención, a pesar de la trascendencia del suceso, el afán ahorrativo que manifiestan los regidores zamoranos (en este caso, quizás obedezca a que parte del gasto debía salir directamente de su propio bolsillo particular). Luego veremos como, a pesar de las precauciones, el gasto fue significativo y hubo nuevamente que recurrir a mecanismos extraordinarios de pago.

El consistorio se reúne otra vez al día siguiente, jueves 28 , también en casa del corregidor, para recibir oficialmente la noticia del óbito mediante la lectura de la cédula del rey Fernando en la que además éste comunica a la ciudad su condición de gobernador del reino y manda que se alcen pendones por doña Juana, una vez tengan lugar los funerales; además, el rey confirma en sus cargos al corregidor y todos sus oficiales y ordena que la ciudad elija procuradores para las Cortes que han de celebrarse en un plazo no superior a treinta días:

«El dicho don Sancho mostro una çedula del rey nuestro señor en que hase saber a la çibdad el fallesçimiento de la reyna nuestra señora e como (tachado: en su testamento) subçedio por heredero en estos reynos la reyna doña Juana nuestra señora e por virtud del testamento que su altesa fiso quedo el dicho señor rey por governador destos reynos con acuerdo de los procuradores de cortes que fueron a Toledo e Madrid e Alcala el año pasado de 503 . Que manda a ssta çibdad que despues de fechas las obsequias que acostunvran e deven faser por su altesa alçen pendones por la dicha reyna doña Juana nuestra señora e que el dicho don Sancho e sus ofiçiales tengan el ofiçio de corregimiento e allcaldias segund que lo han tenido fasta aaquípidio que to cunpliesen obedesçieronla e dieron luego la vara al dicho don Sancho el qual juro de faser e guardar lo que tiene jurado e el dio vara al dicho bachiller allcalde el qual juro e testigos Anton Ferrador e Tremiño andador.

Asymismo mostro un capaçete de la reyna nuestra señora firmada del rey nuestro señor como governador destos reynos en que mandan a esta çibdad que enbie sus procuradores de cortes para dar la obediençia a la reyna nuestra señora donde quier que el rey nuestro señor estoviere dentro de treynta dias despues de la fecha de la carta obedesçieronia e acordaron de echar suertes para el viernes 6 de disienbre e mandaron llamar a los regidores absentes para ello".

La sesión termina con el encargo a los regidores Juan de Porras y Fernando de Ledesma de que organicen todo lo relacionado con las exequias y con la orden de que el escribano envíe cartas a los priores de los monasterios de Montamarta, Moreruela y Valparaiso para que «vengan a ser presentes a las dichas obsequias".

Las actas que se conservan terminan precisamente con los acuerdos de esta sesión del 28 de noviembre de 1504, así que nada sabemos con certeza sobre el desarrollo de los funerales o de las condiciones (cierre de 
tiendas y talleres, etc) y duración del luto oficial. Sin embargo, sí poseemos información sobre los gastos producidos y la forma de hacerlos frente. Por un repartimiento fechado en octubre de $1505^{25}$ sabemos que lo gastado, y lo que se ha de recaudar para hacer frente al gasto, en el acontecimiento fueron 32.268 maravedís, buena parte de ellos invertidos en las ropas de luto de los regidores:

«los 33268 maravedis que montaron en el gasto de çera e otras cosas por menudo que se gastaron en las obsequias de la reyna nuestra señora doña Ysabel que santa gloria aya e en 15 lobas de luto que se dieron a don Sancho de Rojas corregidor que fue desta çibdad e a trese regidores e al escrivano del conçejo que estovieron presentes a las dichas obsequias que ovo en cada loba e capirote e sayon que se les dio 13 varas e media de paño a 100 maravedis la vara el qual dicho repartimiento se fiso por carta de la reyna nuestra señora».

Merced a otro documento del año $1506^{26}$ sabemos que las telas para los ropajes del luto de las autoridades se adquirieron a un mercader vecino de Zamora llamado Ruy López y que costaron 21.150 maravedís de los que trece mil quinientos se le abonaron con cargo al dicho repartimiento y el resto se descontó del salario de los ocho regidores y el escribano del concejo que, en última instancia, estuvieron presentes en los actos fúnebres a razón de ochocientos cincuenta maravedís de cada uno ${ }^{27}$. Por lo deriiás, a lo que parece la vara de paño no costó cien maravedís como se afirmaba en el repartimiento sino ciento sesenta y tres. De manera que, exceptuando las ropas, la ciudad gastó cerca de veinte mil maravedís en la cera y otros ornamentos del funeral real.

25 AHPZ. Fondo Nuevo. Propios. Caja C (catalogación provisional). El monto total del repartimiento, fechado el 11 de octubre de 1505 , es de 93268 maravedís siendo la restante cantidad para pagar el salario del corregidor Diaz Sánchez de Quesada. Existe otra versión de este repartimiento, más amplia, en la que se incluyen otros 200.000 maravedís que se reparten para el reparo del puente y las murallas de la ciudad.

26 Ibidem. Año 1506 s.f. Vid. Apéndice Documental, documento 3.

27 Además del corregidor, los regidores presentes fueron Francisco Enriquez, Juan de Porras, Francisco Docampo, Luís de Mella, Lázaro Gómez de Sevilla, el bachiller Diego Ramírez, Juan de Mazariegos y Fernando de Ledesma y el escribano del concejo Antonio de Ledesma. 


\section{APÉNDICE DOCUMENTAL}

\section{Documento 1}

1501, junio, 20. ZAMORA.

Cuenta de los gastos que hizo la ciudad de Zamora en los regalos que presentó a la señora princesa de Gales con motivo de su estancia en la ciudad y fiestas de toros que se corrieron para cortejarla durante el tiempo que residió en ella.

A.H.N. Diversos. Concejos y Ciudades, legajo 262, doc. n. ${ }^{\circ} 13 / 3$.

f.1r.

Lo que se dio a la señora prinçesa de Gales de serviçio en esta çibdad en 20 de junio, año de 1501

f.1v.

Repartieronse por mandado del rey e de la reyna nuestros señores 40.000 maravedís por esta çibdad e su tierra para pagar el dicho serviçio los quales cobran los procuradores de la çibdad e su tierra e han de acudir con ellos al liçençiado Garçia Gonçalez de Rebolledo allcalde, e las personas a quien se libraron son las siguientes:

f. 2 r.

Los maravedís que se montaron en las cosas que dieron de serviçio a la señora prinçesa de Gales en veynte dias de junio de 1501 años que vino a esta çibdad e las personas a que se han de pagar.

Thomas, confitero

Primero que dio una arroba e nueve libras de conserva de limones a 600 maravedís la libra que montan 816 maravedís 816

Dos arrobas de confites a 400 maravedís montan 800 maravedís .800

41 libras y media de dyaçitron a 45 maravedís la libra que montan 1867 e medio maravedis 1867,5

Dos espuertas en que se llevaron lo susodicho, 40 maravedís ${ }^{28}$ 
Son los maravedís que a de aver el dicho Thomas de las cosas susodichas tres mill e quinientos e veynte e tres maravedis e medio. Averiguaron lo susodicho del dicho Thomas el liçençiado allcalde e Juan Docanpo e Garçia de Ledesma en 25 de junio.

\section{Anton de Ribera}

El dicho dia los dichos allcalde e regidores fisieron quenta con Anton de Ribera . Primero que avia dado para el dicho serviçio treynta cantaron de vino blanco, fueron ygualados en çient maravedís el cantaro que montan tres mill maravedís ${ }^{29}$ 3000 maravedís.

\section{El mayordomo Alonso de la Ribera}

Conpro dies cueros a dos reales que montan 680 maravedís para el dicho vino ${ }^{30}$ .680 maravedís.

f. $2 \mathrm{v}$.

40 costales que se tomaron para llevar la carne

De Martin Gomes dies e seys costales a 37 maravedís segund los ygualo Françisco Arias. Montan 592 maravedís ..................592 maravedís

De Pedro de Cubillos çinco costales al dicho preçio ......185 maravedís Terneras

Alonso Fernandes e Juan de Carvajal e Juan de Almaras e Pedro Fernandes vesinos de Santa Cristina juraron que en 29 de junio de 501 años a cada uno dellos se le tomo una ternera para el presente de la señora prinçesa e que todos las conpraron de los moços despuela e que las tres dellas fueron a 450 maravedís e la una que era de Juan de Almaras que la avian muerto e el dicho Alonso Fernandes juro que otra ternera que se tomo de su suegro Juan Parrado la conpro por otros 450 maravedís. El dicho dia juro Berito Roxo del dicho lugar que su ternera le costo 400 maravedís.

28 En el margen del documento figura la nota siguiente: "Libraron estos maravedís al dicho Thomas en el liçençiado Garçia Gonçalez de Rebolledo allcalde en los dichos maravedís que reçibe para pagar el dicho serviçio en 25 de otubre de 501 años.

Pagole el dicho allcalde los 2585 maravedís e medio dellos e los otros 987 ( $\mathrm{sic}$ ) restantes se le libraron en Pedro de las Pallas e Alvar Garçia procuradores del comun en los maravedís que les cupieron para el dicho serviçio en 8 de abril de 502 años».

29 En el margen del documento: "Libraronse al dicho Anton de Ribera en el liçençiado allcalde el dicho dia 25 de otubre».

30 En el margen del documento: «Libraronse al dicho mayordomo los dichos 680 maravedís en el dicho liçençiado el dicho dia". 
El dicho Juan Marcos juro que su ternera costo 400 maravedís ${ }^{31}$ .3000 maravedís

$3 r$.

\section{Geronimo Vaez}

Paresçio por una çedula de Cristoval de Salamanca que tomo del dicho Geronimo Vaez 33 libras de dyaçitron en dos caxones largos e dos arrobas de confites en una puerta e dies libras de conserva en una olla lo qual contado a los preçios que se ygualo lo que dio Thomas montan en ello lo siguiente:

33 libras de dyaçitron a 45 maravedís montan $1485 \ldots .1485$ maravedís

Dos arrobas de confites a 400 maravedís montan 800.800 maravedís

Dies libras de conservas a 24 maravedís, 240 240 maravedís

La puerta 20 , de la jarra (sic) 17 , de las caxas $50^{32}$ 87 maravedís 2612 maravedis

Cristoval, çerero

Dio 18 hachas que pesaron 94 libras de çera a 46 que montan 4324 .4324 maravedís Alonso Borrego, çerero

Dio 12 hachas que pesaron 54 libras al dicho preçio ${ }^{33} .2460$ maravedís f. 3v.

$$
\text { Garçia de Villafañe }
$$

Dio 20 cargas de çevada a 240 la carga que montan 4800 maravedís $^{34}$ 4800 maravedís

\section{Gallinas}

Dieron 200 gallinas de los conçejos siguientes (no sigue).

31 Al margen del documento: «El dicho dia 25 de otubre se libraron los 3000 maravedís que montan estas syete terneras".

32 Al margen del documento: «En 25 de otubre de 501 años se libraron al dicho Geronimo Vaez estos 2612 maravedís en el liçençiado Garçia Gonçalez de Rebolledo allcalde en los maravedís del serviçio de la señora prinçesa que ha de reçibir».

33 Al margen del documento: «El dicho dia 25 de otubre se libraron en el liçençiado allcalde 6785 maravedís que monto esta çera».

34 Al margen del documento: "Libraronse en el liçençiado al dicho en 25 de otubre». 
f. 4 r.

\section{Toros}

Dieronse tres toros que costaron 9100 maravedís y de la costa de traer 1000 maravedís. Las personas que los han de aver:

Miguell Juan vesino de Mayalde un toro $320{ }^{35} \ldots \ldots \ldots . .3200$ maravedís

Martin de Ledesma de otro toro $3400^{36}$ 3400 maravedís

Miguell de Malillos ha de aver de otro toro 2500 2500 maravedís

Miguell carniçero de la costa de traerlos a de aver mill maravedís 1000 maravedís

En 15 de avril de 502 años a Gomes Maldonado 200 maravedís que se le quedaron del camino que fue a Valladolid a los señores del Consejo el año pasado de 501 años en que estovo ocho dias de mas de los 365 maravedís que le dio el mayordomo Alonso de la Ribera e que ge los den Pedro de las Pallas e Alvar Garçia procuradores del comun.

Documento 2.

Pepartimiento para el pago del servicio a la señora Princesa de Gales $y$ otros asuntos. Año 1501.

A.H.P.Z. Fondo Municipal Nuevo. Propios. Caja C-1. (signatura provisional)

f.1r.

Repartimiento fecho por mandado del Rey e Reyna nuestros señores por virtud de una carta sellada con su sello e librada de los señores de su muy alto consejo de quarenta mill maravedís para pagar el serviçio questa çibdad fiso a la serenisyma señora prinçesa de Gales al tienpo que paso por esta çibdad en dies e nueve dias del mes de junio deste presente año de quinientos e un años. El qual dicho repartimiento mandan sus alteças que se faga en esta çibdad por sisa e en la tierra por repartimiento. E de 12000 maravedís por carta de sus alteças librada del presi-

35 Al margen del documento: «Libraronsele al liçençiado allcalde en 25 de otubre de 501 años todos estos toros».

36 Al margen del documento: «Que no le pago el liçençiado allcalde estos 3400 maravedis, se le libraron en primero de abril de 502 años en Pedro de Avila platero en el alcançe que se les hiso a los procuradores». 
dente e oydores de la chançilleria de Valladolid para seguir çiertos pleytos que en ella trae la çibdad por que no ay en ella propios de que se seguir. E tres mill maravedís que se reparten por mandado de los señores justiçia e regidores con consentimiento de los procuradores del comun desta çibdad e de su tierra para el escrivano del conçejo segund se ha fecho los años pasados porque faga todos los repartimientos que se han fecho e ovieren de faser en la dicha çibdad e su tierra e les de syn otros derechos los abtos e escripturas que ante el dicho escrivano del conçejo pasaren tocantes a los buenos onbres del comun desta çibdad e su tierra este dicho presente año. E seys mill maravedís para Pedro de Fermoselle notario que se reparten por los lugares de la tierra de la dicha çibdad que los procuradores de la tierra estavan obligados de le dar del año pasado de quinientos e deste presente año de quinientos e uno porque tenga cargo de tomar los traslados de los privillegios de los juros que estan sytuados en los lugares de la dicha tierra. El qual repartimiento de los dichos seys mill maravedís se fase por mandado de los dichos señores justiçia e regidores por pedimiento e consentimiento de los dichos procuradores de la tierra. $\mathrm{E}$ mas se reparten en el partido de tierra del pan dos mill e quinientos maravedís que Cristoval Chicote procurador del dicho partido pidio que se le diese liçençia para repartirlos para çiertos gastos cunplideros a los lugares del dicho su partido $€$ los dichos señores dieron liçençia para los repartyr de que el ha de dar quenta. Con los quales maravedís han de acudir en la tierra de vino a Pedro Baylador vesino de Corrales e en Sayago a Juan Gallego vesino de Pereruela e en tierra del pan al dicho Cristoval Chicote por quanto a su pedimiento de los dichos procuradores se mando asy e los dichos reçebtores los han de pagar a los dichos procuradores e ellos han de traer los dineros a esta çibdad para que se paguen a quien los oviere de aver. Los quales dichos maravedís se reparten en la manera que de yuso sera contenida. $\mathrm{E}$ montan todos los maravedís que se reparten en este repartimiento sesenta $\theta$ tres mill e quinientos maravedís.

Cabe a los buenos onbres del comun desta çibdad de lo de la señora prinçesa que se ha de echar en sisa 5440 maravedís. E de los 12000 maravedís para los pleitos cabeles 1680 maravedís. Y de los 3000 maravedís del escrivano del conçejo les caben 400 que son todos syete mill e quinientos e veynte maravedís

.7520

f.1v.

Cabe a la tierra del vino de lo de la señora prinçesa e de lo del escrivano del conçejo e de lo de Pedro de Fermoselle veinte e dos mill e ochoçientos e quarenta e tres maravedís ......................................22843 
Cabe al partido de Sayago de las cosas sobredichas en el capitulo antes deste dies e nueve mill dosientos e treynta e çinco maravedís. 19235

Cabe al partido de la tierra del pan de las cosas sobredichas e de los 2500 maravedís que se reparten mas en este partido catorse mill e tresientos e ochenta e tres maravedís 14383

Los sobredichos sesenta e tres mill e quinientos maravedís que se reparten en la manera que dicha es los han de pagar daqui a en fin de setienbre deste presente año e fueron mandados cojer los dichos maravedis en consystorio en el mes de jullio e agosto e setienbre deste dicho año segund esta asentado en el libro de los acuerdos del consystorio a lo qual fueron presentes Alonso de Villalobos e Geronimo Sanches procuradores del común de la çibdad e ....Martín procurador de tierra del vino e Martín Juan procurador de Sayago e Cristoval Chicote procurador de tierra del pan. E sale la cañama en tierra de vino e en Sayago a 35 maravedís e en tierra del pan a quarenta e dos maravedís.

\section{Documento 3.}

Relación de las cantidades embargadas al corregidor, regidores y escribano del concejo de Zamora de sus salarios del año 1506 para hacer frente a algunas deudas generadas por las exequias hechas por el fallecimiento de la reina Isabel. Año 1506.

A.H.P.Z. Fondo Municipal Nuevo. Propios.Caja C-1 (signatura provisional).

f. 1 r.

La muy noble e leal çibdad de Çamora justiçia e regidores della mandamos a vos Anton Ferrador nuestro mayordomo que de los maravedis del repartimiento que se fiso el año pasado de quinientos e çinco por esta çibdad e su tierra por las obsequias e lutos de la reyna doña Ysabel nuestra señora que aya santa gloria e de los salarios que han de aver desta çibdad las personas de yuso contenidas este presente año de la fecha desta carta del terçio segundo del dicho año dedes a Ruy Lopes mercader vesino desta çibdad veynte e un mil e çiento e çinquenta e quatro maravedis e medio que le son devidos e ovo de aver del luto que dio a las dichas personas en esta guisa:

A don Sancho de Rojas corregidor que fue deste çibdad trese varas e media de paño dies e ocheno de Segovia a çiento e sesenta e tres mara- 
vedis la vara los quales le aves de pagar de los maravedis del dicho repartimiento mil e tresientos e çinquenta maravedis 1350

A don Françisco Enriques regidor otro tanto paño al dicho preçio en que montan dos mil e dosientos maravedis e medio de que le aves de pagar los mill e tresientos e çincuenta maravedis del dicho repartimiento e los ochosientos e çinquenta maravedis e medio de su salario $.2200,5$

A Juan de Porras regidor otro tanto paño (se repite el texto en todos)..........................................................2200,5

A Françisco Docampo regidor .................................................2200,5

A Luys de Mella regidor........................................................2200,5

A Lasaro Gomes regidor ....................................................2200,5

Al bachiller Diego Ramires regidor .......................................2200,5

A Juan de Masariegos regidor.................................................2200,5

16753,5

f.1v.

A Ferrando de Ledesma regidor otras trese vara e media del dicho paño 2200,5

A Antonio de Ledesma escrivano del conçejo yuso escripto otro tanto paño 2200,5

Asi que son los dichos veynte e un mill e çiento e çinquenta e quatro maravedis los que aveys de dar e pagar al dicho Ruy Lopes en la manera que dicha es los quales le fueron mandados librar en vos en consystorio e tomades su carta de pago con la qual e con esta vos estan reçibidos en quenta los dichos veynte e un mill ə çiento e çinquenta e quatro maravedis e medio e los dichos maravedis de los salarios de las dichas personas les descontad de los libramientos que vos dieren de los del dicho terçio segundo deste dicho año e detened en vos de los dichos derechos desta librança del escrivano del conçejo dosientos e onse maravedis e medio e acudidle con ellos. 